\title{
Visografia: uma nova proposta de escrita da língua de sinais
}

\author{
Visography: a new written proposal for the sign language \\ Claudio Alves Benassi ${ }^{1}$

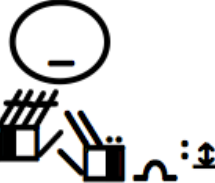 \\ Universidade Federal de Mato Grosso
}

- RESUMO: Neste artigo, pretendemos apresentar a Escrita da Língua de Sinais (ELS) VisoGrafia, desde sua concepção até a testagem em um curso de ensino de extensão, na Universidade Federal de Mato Grosso (UFMT). Essa proposta de grafia para as Línguas de Sinais surge de nossas inquietações frente ao ensino de ELS, no curso de Letras-Libras Licenciatura da UFMT, cujos alunos não apresentaram boa aderência aos sistemas de ELS correntes. A VisoGrafia nasce da junção de caracteres e regras grafotáticas do SignWriting (SW) e da Escrita das Línguas de Sinais (ELiS), sistemas que influenciaram fortemente em sua criação, além da interação com alunos ouvintes e visuais ${ }^{2}$ (surdos) do curso de LetrasLibras - Licenciatura da UFMT. Nossa fundamentação teórica vem dos autores Barros, Barreto e Barreto, Olviedo, entre outros. O sistema se encontra totalmente constituído, testado e em fase de divulgação. Esperamos com este artigo, trazer ao conhecimento da comunidade acadêmica, esta proposta de grafia cuja viabilidade de leitura e de escrita foi testada com êxito.

- PALAVRAS-CHAVE: VisoGrafia; Escrita da Língua de Sinais; Escrita de Sinais; Libras

- ABSTRACT: In this article, we intend to present the Sign Language Writing (SLW) VisoGraphy, from its conception to the testing in an extension teaching course, at the Federal University of Mato Grosso (UFMT). This proposal of writing for sign languages arises from our questions regarding the teaching of SLW, in the course of Letras-LIBRAS Graduation of UFMT, whose students did not present good adherence to the current SLW systems. VisoGraphy comes from the combination of SignWriting (SW) and Sign Language Writing (ELiS), systems that strongly influenced its creation, as well as interaction with hearing and visual (deaf) students of the Letras-LIBRAS - Graduation of UFMT. Our theoretical foundation comes from the authors Barros, Barreto and Barreto, Olviedo, among others. The system is fully constituted, tested and in the process of being disseminated. We hope with this article to bring to the attention of the academic community, this proposal writing whose feasibility of reading and writing has been tested successfully.

- KEYWORDS: VisoGraphy; Sign Language Writing; Sign Writing; LIBRAS

\footnotetext{
${ }^{1}$ Mestre em Estudos de Cultura Contemporânea pela UFMT. Doutorado em andamento em Estudos de Linguagem pela UFMT.

${ }^{2}$ Termo conceitual delineado pelo pesquisador Anderson Simão Duarte (UFMT), para designar a pessoa que emite e capta mensagens linguísticas por meio do canal visual, levando em consideração que não se separa o sujeito da língua que o constitui ideologicamente. Assim sendo, o ouvinte é caracterizado pela língua oral/auditiva e o visual pela língua espaço/visual e não pela ausência da audição (DUARTE; BENASSI; PADILHA, 2016). Este termo corrobora a terminologia utilizada pela linguista visual Ana Regina e Souza Campello, que utiliza em seu livro "Língua Brasileira de Sinais" (2011), o termo sinalizante visual.
} 


\section{Explicações preliminares: breve histórico da ELS}

A grafia da Escrita de Língua de Sinais (ELS) surgiu da iniciativa do educador guadalupenho Roch Ambroise Auguste Bébian (1789-1839), que segundo Olviedo (2009, p. 294) "foi uma figura essencial na história da surdez", que apesar de muito citado, "é muito pouco conhecido". Bébian desenvolveu um sistema de ELS denominado Écrire les Signes Mimographie, que para Olviedo (op. cit.) é sua obra mais importante. A Mimographie é considerada de base alfabética por grafar as mínimas partes das LS, ou seja, grafa os parâmetros configurações de mão juntamente com orientação de palma, locação ${ }^{3}$, movimentos e expressões não manuais. Aguiar e Chaibue (2015, p. 05) afirmam que a Mimographie tem um total de 190 símbolos, que são escritos da esquerda para a direita, sendo estes, em sua maioria icônicos, facilmente recordados.
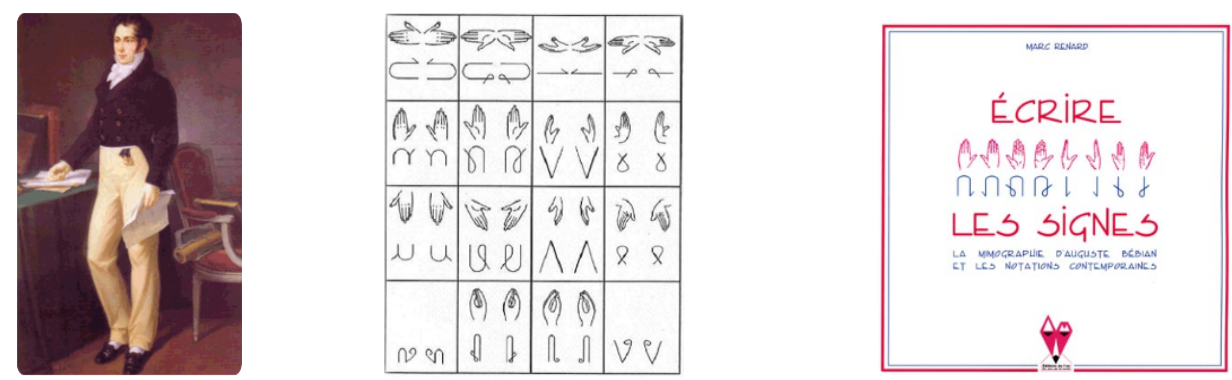

Figura 01. A esquerda: Bébian; ao centro: grafia das Configurações de Mão (CM) e; a direita: capa do livro Écrire les signes (Marc Renard). Fonte: Disponível em http://www.usm67.fr/sourdshistoriques.html. Consulta em 19 de set. 2014.

Apesar do pioneirismo de Bébian em divulgar um sistema de grafia capaz de registrar paremicamente ${ }^{4}$ as LS, o grande marco na história da ELS foi a publicação de um sistema de notação capaz de registrar as LS para fins de investigação, pelo linguista Willian C. Stokoe (1919-2000), em 1965 (op. cit.). A Notação de Stokoe (como ficou conhecida) influenciou várias outras gerações de pesquisadores que desenvolveram suas ideias e as ampliaram em seus próprios sistemas de grafia das LS. Segundo Barreto e Barreto (2012, p. 35) e Stumpf (2011, p. 63), a Notação de Stokoe se propunha a grafar os cinco grupos de paremas ${ }^{5}$ das LS. Para Stumpf (2011, p. 63), o sistema visava atender as necessidades de grafia do próprio linguista.

Vários outros sistemas foram desenvolvidos ao redor do mundo, desde então. Dentre eles podemos citar o HamNoSys (BARRETO, BARRETO, 2012, p. 35; BARROS, 2006, p. 389) e o D'Sign (BARRETO, BARRETO, 2012, p. 36, 37). No Brasil temos três sistemas correntes. São eles o SW, a ELiS e o Sistema de Escrita de Língua de Sinais (SEL). O SW foi criado pela norte-americana Valerie Sutton, em 1974, na Dinamarca segundo Barreto e Barreto (2012, p. 38). Sua criação teve como base, a escrita da dança denominada Dacing Writing. É um sistema de escrita vertical, da esquerda para a direita, que apesar de ter 900 caracteres aproximadamente (BENASSI, 2017, p. 28), e ser considerado denso e pesado pelo exacerbado detalhamento da escrita (BENASSI, et al, 2016, p. 721). O SW é usado em mais de 40 países, inclusive o Brasil.

A ELiS foi criada pela professora Mariângela Estelita Barros da Universidade Federal de Goiás (UFG), no ano de 1997 (BARROS, 2006, p. 390), segundo a autora, fortemente influenciada pela Notação de Stokoe. A ELiS é de estrutura linear, baseada em pesquisa linguística, de base alfabética e de princípio econômico (BARROS, 2015, p. 17). Atualmente, a ELiS conta com uma fonte desenvolvida que ao ser instalada em computador, permite a

\footnotetext{
${ }^{3}$ Pode ser referenciada também com ponto de articulação ou ponto de contato.

${ }^{4}$ Termo referente a parema.

5 Parema é a unidade mínima do plano de expressão das línguas de sinais que não possuem, em si mesmas, significado algum, combinam-se entre si para formar sinalicos morfêmicos ou sinalicos distintivos (BENASSI, 2017, p. 131, 132. Grifo do autor). (Fazer ajuste do texto)
} 
elaboração de textos no software Word, fato que faz dela, um dos mais promissores sistemas de ELS, correntes no Brasil. Dentre as universidades que já utilizam e difundem essa ELS podemos citar a UFG, a Universidade Federal da Grande Dourados (UFGD) e a UFMT, por meio da minha atuação.

Já o SEL foi criado em abril de 2009, pela professora Adriana Stela Cardoso Lessa de Oliveira, da Universidade Estadual do Sudoeste da Bahia (UESB), sendo que em 2011, a autora chega a uma versão satisfatória de seu sistema de ELS (2012, p. 150). A ELS de Lessa-deOliveira grafa três elementos específicos das LS, que para a mesma, são formadores dos sinais, denominados de MLMov. São eles a mão (incluindo configuração e orientação da palma), a locação e o movimento.

Apesar de circular no Brasil os três sistemas listados anteriormente, a escrita de sinais não é uma realidade na alfabetização do sujeito visual, ainda que diversas pesquisas reconheçam a sua importância no desenvolvimento cognitivo do mesmo. Segundo Nobre (2011), a escrita de sinais colabora para o desenvolvimento do pensamento reflexivo, instrumentaliza a reflexão, colabora na aprendizagem de outras línguas escritas, permite a comunicação escrita fluente, entre outras. Para Stumpf (2011), a ausência da aprendizagem da escrita de sinais, provoca no cognitivo do visual, a constituição de inúmeras lacunas, que segundo a pesquisadora dificilmente poderão ser preenchidas ao longo de sua vida.

Tendo em vista o conhecimento dos benefícios da aprendizagem da escrita de sinais e também os prejuízos da ausência dela na alfabetização do visual, além dos motivos que fazem com que as mesmas não sejam fixadas, tais como excesso de caracteres, exacerbado detalhamento da grafia e abstração dos sistemas, empreendi uma pesquisa no intuito de fundir o SW e a ELiS, simplificando assim o sistema de escrita ao assimilar os aspectos mais visuais e simples do SW e, consequentemente, diminuindo o número de caracteres assumindo a característica alfabética (que grafa as mínimas partes da língua) e linear da ELiS.

\section{VisoGrafia: o surgimento}

Minha inserção na Libras se deu em 2011, quando cursei a disciplina de Libras na graduação de Música. Em 2013, iniciei os estudos de SW que abandonaria um ano e meio depois, pelas dificuldades encontradas na aprendizagem do mesmo. Em 2014, pelo advento de minha entrada na UFMT como professor substituto, foi me atribuída a disciplina Escrita de Sinais, sendo que na época, tive que viajar para Goiânia para aprender a ELiS.

A partir daí, a ELS ganha significante destaque em minha vida acadêmica e na Libras. Inseri a ELiS em minha prática de aquisição de Libras como L2, sendo ela então, um divisor de águas no meu desenvolvimento linguísticos da LS. Ao ministrar a disciplina de Escrita de Sinais, muitos dos acadêmicos (incluindo ouvintes e visuais), as dificuldades não demoraram a surgir. As primeiras aulas eram "tranquilas", mas quando chegávamos a escrita de sinais bimanuais quase simétricos, haviam completa rejeição desse sistema de ELS.

Preocupado com a situação, ante a rejeição dos alunos e a exaltação da visualidade do $\mathrm{SW}$, comecei a escrever sinais por este sistema e a pedir que os alunos lessem, e confirmando minha hipótese, poucos eram os sinais que eram decodificados pelos acadêmicos. A partir daí alguns questionamentos passaram a me inquietar, tais como:

Por qual motivo a ELiS é recusada? O sistema é visual e também abstrato, tal qual o SW que também não se fixa. [...] Poderiam os aspectos simples dos dois sistemas serem relidos em uma nova proposta de grafia? (BENASSI, DUARTE, PADILHA, 2016, p. 35).

Tendo em vista essas preocupações e as pesquisas divulgadas no Brasil, sobre os benefícios da ELS para o desenvolvimento do sujeito visual, tais como, aquisição de outras línguas escritas e a comunicação escrita fluente, o que não acontece na utilização do sistema de grafia da língua oral (BARRETO, BARRETO, 2012; NOBRE, 2011), iniciei uma busca pelas possibilidades da escrita da Libras por meio da ELiS, buscando ordená-la de acordo com algumas regras grafotáticas do SW. 


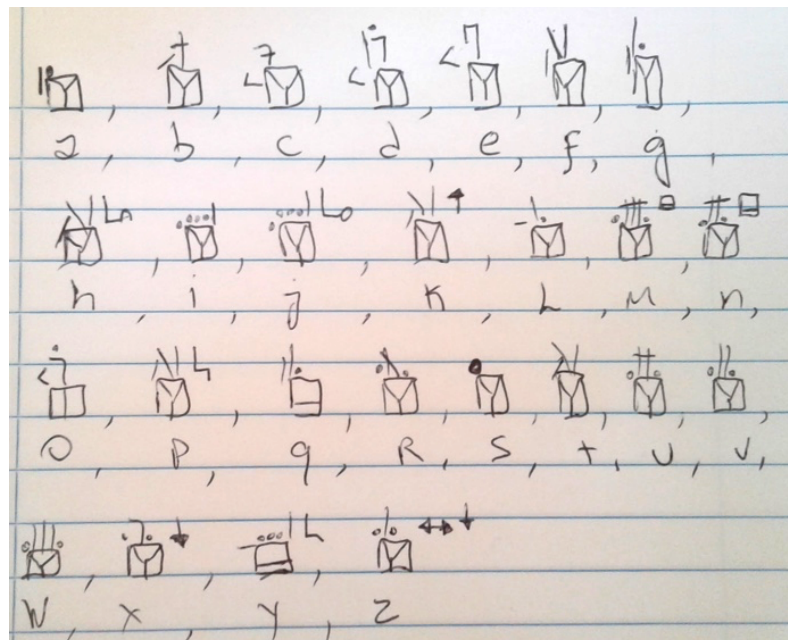

Figura 02. Primeira versão do alfabeto manual. Fonte: acervo do autor.

As primeiras tentativas foram as de escrever o alfabeto manual. Antes mesmo de chegar a uma versão satisfatória do alfabeto, comecei a testar a escrita de sinais. A princípio, as configurações de mão eram escritas como na ELiS, levando em consideração sua regra grafotática de que a configuração de mão se divide em configurações de dedos. Estas se forem iguais, pelo princípio de economia da escrita, escreve-se representa apenas um visografema. Assim, alfabeto manual e sinais eram grafados de acordo com as figuras de números 02 e 03.

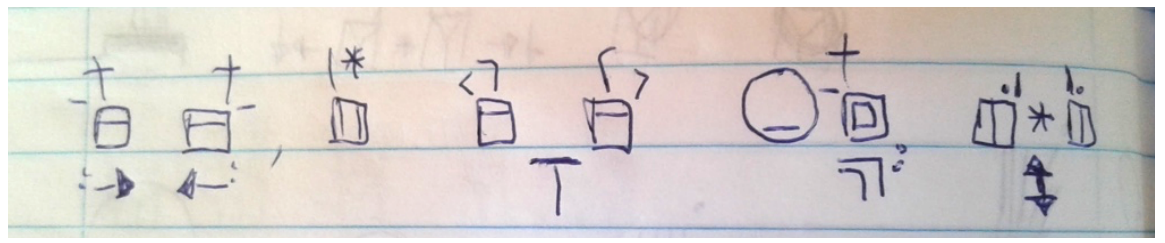

Figura 03. Frase HOJE, EU QUERO COMER ARROZ. Fonte: acervo do autor.

Segundo Benassi, Duarte e Padilha (2016, p. 36, 37), os primeiros sinais escritos foram: APRENDER, LARANJA/SÁBADO, OUVIR e CHEIRAR. Segundo os autores (op. cit.), os sinais escritos foram mostrados ao professor Anderson Simão Duarte, que mesmo sem conhecer profundamente as ELS utilizadas como base para a nova escrita, descodificou rapidamente as informações em Libras, o que provava a viabilidade da mesma.
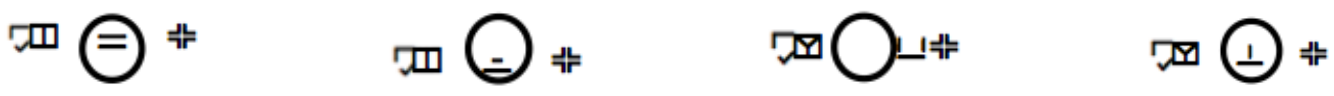

Figura 04. Sinais APRENDER, LARANJA/SÁBADO, OUVIR e CHEIRAR, respectivamente. Fonte: Benassi (2016).

Como se pode notar, a ordem dos visografemas (letras) da ELiS foi mantida em quase sua totalidade. A configuração de mão passou a ser escrita na orientação de palma (semelhante ao $\mathrm{SW}$ ) e a locação passou a ser escrita dentro do visografema que representa a cabeça (no caso dos sinais). $\mathrm{Na}$ frase como se pode perceber a verticalidade dos visografemas faz alusão a ELS SW.

Os estudos subsequentes me levaram a seleção de visografemas da ELiS e do SW, e também as adaptações que originaram o visograma (alfabeto) da VisoGrafia. A sua primeira versão, possuía um total de 64 símbolos (BENASSI, et al, 2016, p. 723), número muito inferior aos do SW (900) e da ELiS (95). A partir de então, testes quanto a viabilidade da escrita e da 
leitura foram realizados com acadêmicos e profissionais da Libras, ouvintes e visuais com pouco ou nenhum conhecimento da ELS.

\section{VisoGrafia: o visograma}

Após o início do curso de extensão, ofertado pela Direção do Instituto de Educação (IE) da UFMT, definiu-se então o alfabeto da VisoGrafia, além das mudanças em visografemas que já eram utilizados. Ainda, com a colaboração dos cursistas, mudanças na estrutura da VisoGrafia foram implementadas ${ }^{6}$, que não convém apresentarmos aqui. Das convenções mais significativas implementadas em parcerias com os alunos do curso de VisoGrafia, foi a separação dos visografemas e dos diacríticos, pelo entendimento que os visografemas são preponderantes para o registro da informação na escrita visogramada. Já os diacríticos em determinados contextos podem ser dispensáveis, como por exemplo, os diacríticos utilizados para grafar as expressões não manuais.

O entendimento expresso por Barros $(2008,2015)$ de que muitos sinais e contextos, conduzem o visossinalizante ${ }^{7}$ ao uso da expressão adequada, tornando sua escrita desnecessária, fato que tornou a ELiS uma grafia leve e prática, foi corroborado pelos cursistas aprendizes da VisoGrafia. Primeiramente, apresento uma tabela contendo apenas os visografemas do visograma da VisoGrafia, sendo que na sequência, será então apresentado o quadro com os diacríticos da nossa ELS, que podem ser utilizados para completar a grafia de um determinado sinal ou incrementar o registro da informação por ela grafada.

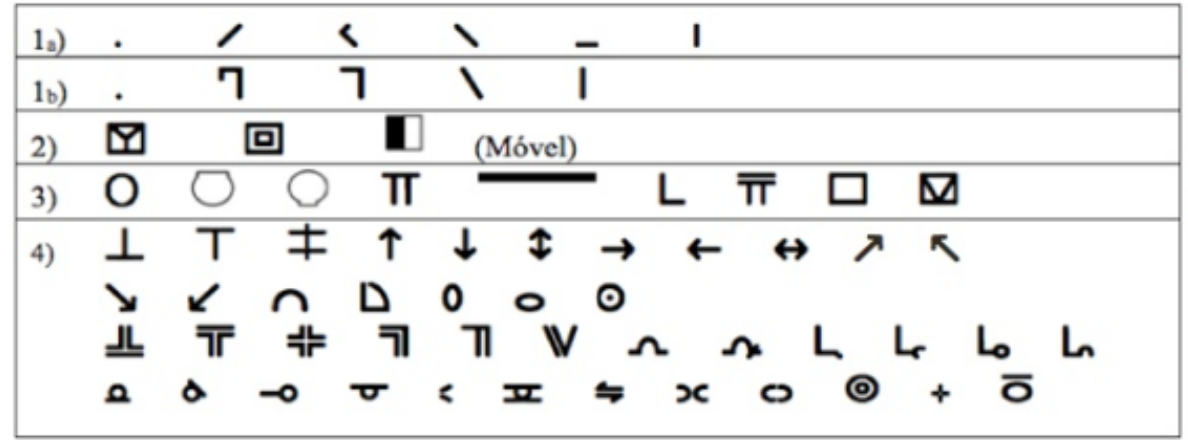

Figura 05. Primeiro visograma da VisoGrafia, com um total de 64 visografemas. Fonte: elaborado por Claudio Alves Benassi.

Após o curso de extensão, com a colaboração dos cursistas ouvintes e visuais (surdos), o número de caracteres caiu de 64 para 46. Isso por que alguns visografemas de configuração de dedos, orientação de palma se tornaram moveis (podem ser girados em quaisquer direções) e também, ao fato de que os visografemas de movimentos faciais e corporais (expressões não manuais), foram rebaixados para a categoria de diacríticos, haja vista o número muito restrito de sinais em que os mesmos figurariam como visografemas.

\footnotetext{
${ }^{6}$ No livro "O despertar para o outro: entre as escrita de língua de sinais" (BENASSI, 2017), são apresentadas essas mudanças e convenções.

7 Termo conceitual elaborado como desdobramento do termo visual. Segundo Pereira e Benassi (2016, p. 02) Visosinalizante é o indivíduo que apreende e compreende o mundo por meio da Língua de Sinais (LS) e nele se expressa sinalizadamente.
} 


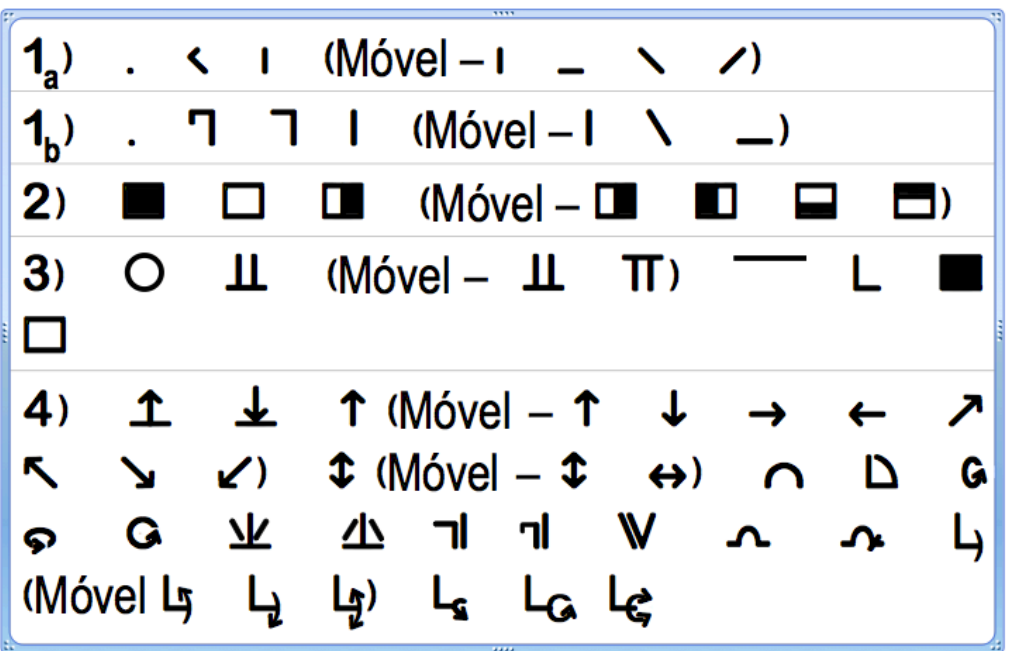

Tabela 06. Terceiro visograma da VisoGrafia. Fonte: elaborado por Claudio Alves Benassi.

Em março e maio de 2017, a VisoGrafia foi aplicada em duas disciplinas de ELS de cursos de Licenciatura em Letras-Libras. No primeiro curso que é semipresencial, a turma é composta por alunos surdos e ouvintes. Neste, os encontros acontecem nos finais de semana, um encontro por mês. Apliquei a VisoGrafia e os resultados foram surpreendentes: na primeira aula os acadêmicos conseguiram ler e escrever datilologia, por meio da VisoGrafia; na segunda, os mesmos leram sinais isoladamente e escreveram o próprio sinal (sinal nominal) (BENASSI, 2017, p. 120, 121).

No segundo curso, a modalidade é presencial modular. A turma é a terceira admitida pelo curso e é composta somente por alunos ouvintes. Em relação as duas primeiras aulas, o resultado foi similar aos do primeiro curso. Com oito aulas apenas, os alunos escreveram pequenos textos, tais como, fábulas, descrição das férias, além da criação de jogos didáticos para o ensino da VisoGrafia (BENASSI, 2017, p. 122, 123).

Após a coleta destes dados, a VisoGrafia passou por uma grande reforma. Alguns visografemas admitidos da ELiS, foram modificados, outros excluídos e alguns foram criados em parceria com os alunos de ambos os cursos mencionados acima. Todas essas mudanças foram amplamente discutidas com os usuários da VisoGrafia (alunos das disciplinas de ELS e do curso de extensão de ELS.

Com a aplicação da VisoGrafia na redação da tradução dos resumos para a Libras, dos artigos publicados pelas revistas Diálogos e Falange Miúda, percebi a necessidade da inserção de novos visografemas. Com os novos caracteres inseridos no visograma do nosso sistema de escrita de sinais, o número de visografemas atual passa a ser de 37 , conforme figura a segui.

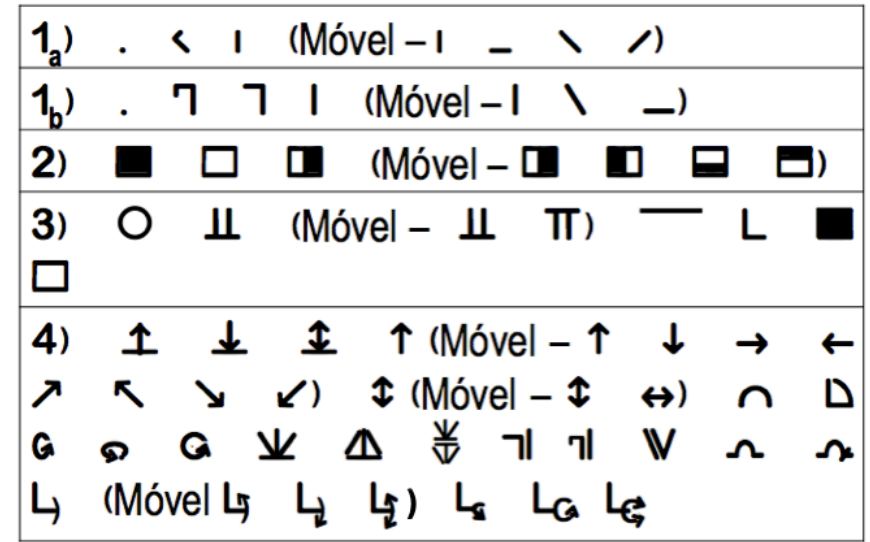

Figura 07. Visograma atual da VisoGrafia. Fonte: Benassi (2017, p. 129). 


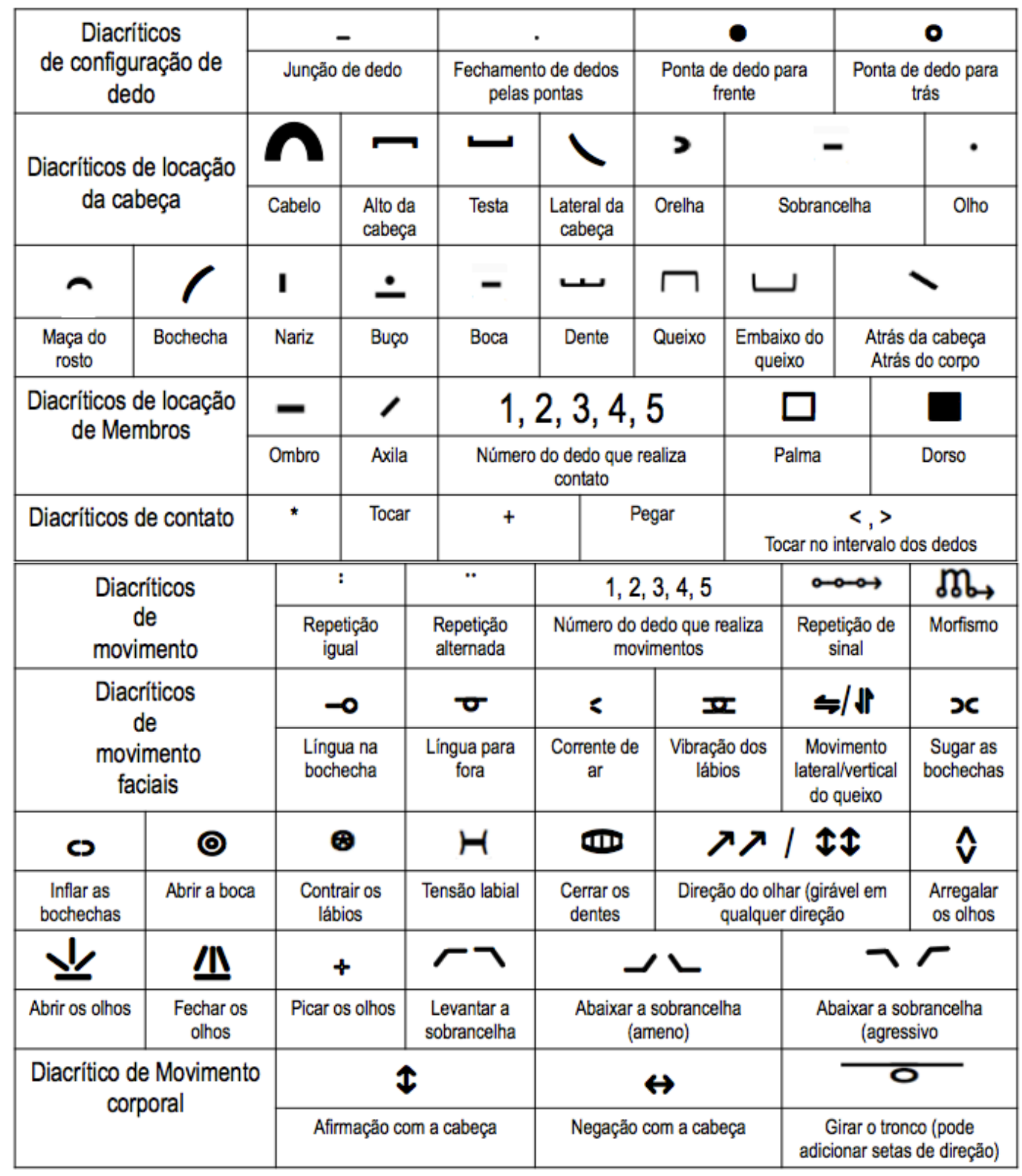

Figura 08. Quadro de diacríticos da VisoGrafia. Fonte: Benassi (2017, p. 130).

A figura 07 mostra que a VisoGrafia apresenta um total de 55 diacríticos. Isso poderia tornar a grafia pela nossa ELS pesada se todos esses diacríticos fossem essenciais para o registro dos sinais das LS. No entanto, como pode ser comprovado no curso de extensão, uma boa parcela dos diacríticos da VisoGrafia, só são utilizados para uma escrita mais complexa. Isso indica que em um estágio básico, é necessário aprender, apenas, os 38 visografemas e diacríticos de configuração de dedo, contato e movimento (', "’, 1, 2, 3, 4, 5) para conseguir grafar a LS, sendo que os demais são dispensáveis.

\section{VisoGrafia: viabilidade da escrita}

A viabilidade da escrita das LS e da Libras, será comprovada pelo registro do poema Sentimentos (2015) de Duarte (Formiga em arte) e de sinais de outras LS, conforme tabelas a seguir.

1) dois sinais da Língua mexicana de sinais: 


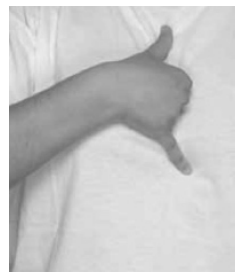

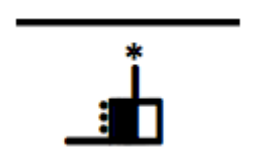

$(\mathrm{Eu})$

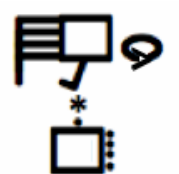

(Café)

Fonte: elaborado por Claudio Alves Benassi. Imagens disponíveis em Fleischmann e Pérez (2011: 25,28).

2) dois sinais da Língua chilena de sinais:

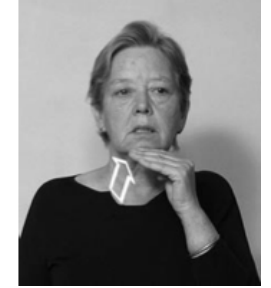

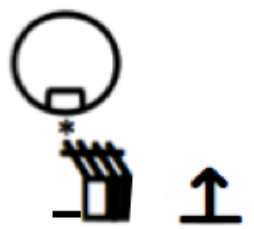

(Igual)

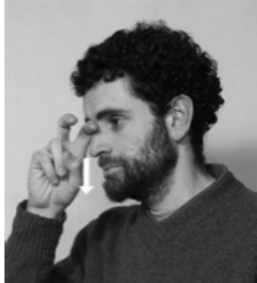

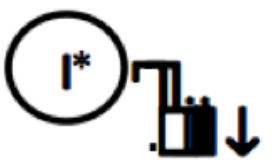

(Igual - Semelhança entre pessoas)

Fonte: elaborado por Claudio Alves Benassi. Imagens disponíveis em Robertson, Quintela e Ramírez (2009: 24,25).

3) dois sinais em Língua colombiana de sinais:

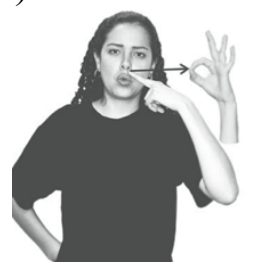

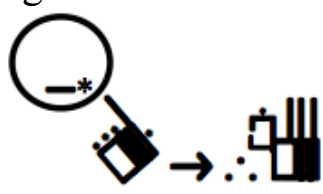

(Homem)

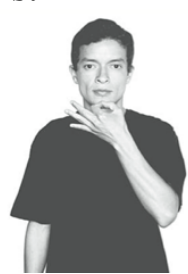

(Homossexual)

Fonte: elaborado por Claudio Alves Benassi. Imagens disponíveis em Diccionario básico de la lengua de señas colombiana (2006: 08).

4) uma frase em Libras:

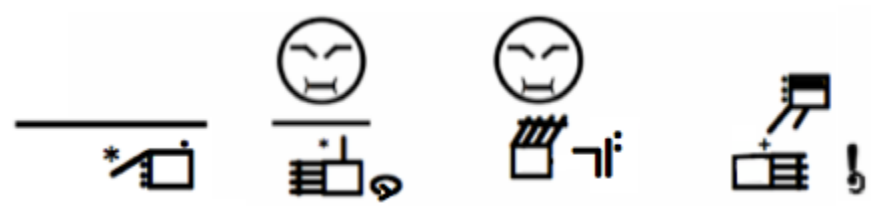

EU GOSTO DE COMER CARNE (Irônico)

Fonte: elaborado por Claudio Alves Benassi. 


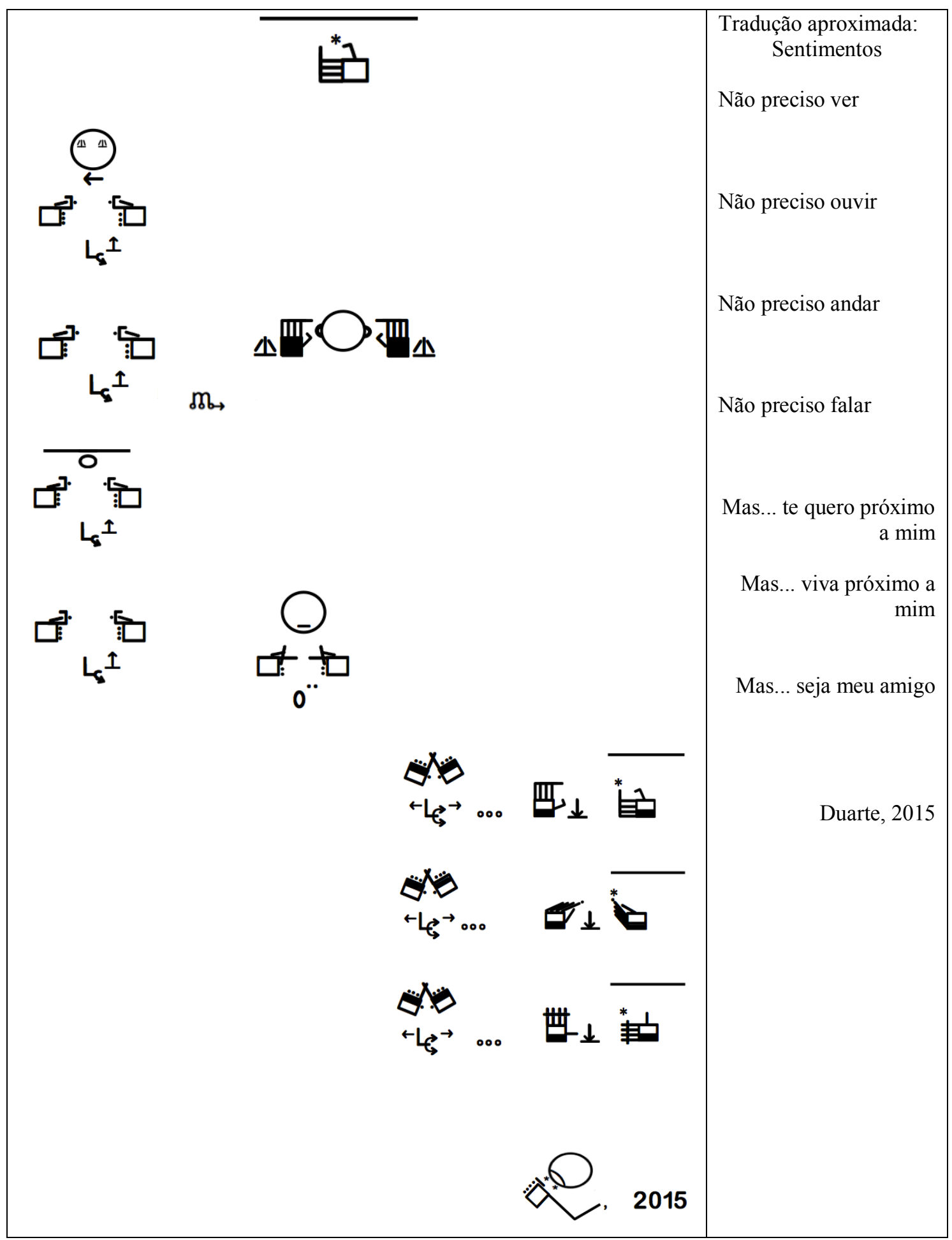

Fonte: Benassi, Duarte e Padilha (2016).

Além desses, muitos outros experimentos de grafia foram realizados. Atualmente, dois periódicos científicos adotam a VisoGrafia em suas publicações. A Revista Diálogos (RevDia), que desde 2014, publica o resumo de seus artigos em escrita de sinais ELiS no segundo número de 2017, adotou a VisoGrafia e publicou seu dossiê temático "Afinação em flores e frutos" com todos os resumos dos artigos que a compõe em Libras escrita pela VisoGrafia. A Revista Falange Miúda (ReFaMi), revista discente de graduação e especialização, também em seu 
segundo número de 2017, publicou todos os resumos de seus artigos em Libras escrita pela VisoGrafia.

As publicações foram possíveis graças ao trabalho de dois acadêmicos, figuras centrais na editoração textual em VisoGrafia. São eles o professor Claudio Alves Benassi, desenvolvedor desse sistema de escrita de sinais e o acadêmico e profissional da área da computação Itacir Cabral, O primeiro escreveu sinais da Libras em VisoGrafia, formando um banco de sinais, que possibilitou por meio do aplicativo "Arranja Sinais" desenvolvido pelo segundo, editar os textos de forma rápida e confortável. O pequeno processador de texto está em sua versão beta e no momento passa por adequações. Em breve será disponibilizado para download gratuito no site www.visografia.com.

\section{VisoGrafia: viabilidade da leitura}

Os experimentos para a leitura da VisoGrafia foram realizados em maio de 2016. Foram escritos sinais da Libras e entregues aos profissionais e acadêmicos da Libras que tinham pouco ou nenhum conhecimento das ELS. Embaixo de cada sinal escrito pela VisoGrafia (primeira versão), era dado um espaço para que o leitor pudesse grafar em língua portuguesa o significado do sinal escrito. Caso houvesse dificuldades para a realização da leitura, explicações eram dadas de acordo com a necessidade, sendo que tais explicações e o tempo da leitura eram anotados.

Benassi et al (2016) ao analisarem o procedimento de leitura por duas profissionais e acadêmicas da Libras, sendo elas identificadas na pesquisa como RS que tem conhecimento básico de ELiS e LS sem nenhum conhecimento das ELS, contataram que ambas realizaram a leitura em um tempo considerado pequeno, sendo que RS demorou três minutos e necessitou de explicações sobre configuração de mão. Enquanto que LS levou oito minutos, aproximadamente, demonstrando dificuldades nas configurações de mão, orientação de palma e movimento. Tendo ambas recebido quatro sinais ${ }^{8}$ para leitura, LS confundiu o sinal BISCOITO com PERIGO.

Benassi e Padilha (no prelo) realizaram a análise da leitura realizada por duas outras profissionais e acadêmicas da Libras $\mathrm{A}_{1}$ e $\mathrm{A}_{2}$, sem nenhum conhecimento das ELS. Nesta parte do experimento, ambas as pesquisadas receberam sinais escritos idênticos (LARANJA/SÁBADO; OUVIR/OUVINTE; ESTUDAR e VER). O processo de descodificação de $\mathrm{A}_{1}$ durou cinco minutos, com demanda de algumas explicações sobre orientação de palma e movimento, enquanto que $\mathrm{A}_{2}$ demorou quatro minutos e 40 segundos, demandando explicações sobre a escrita da orientação de palma e dos movimentos.

Os experimentos de leitura da VisoGrafia por acadêmicos, intérpretes e professores de LS mostram que a mesma é uma escrita visual e simples, cuja descodificação no processo de leitura dos acadêmicos selecionados para o experimento, sem conhecimento ou pouco iniciados na ELS, demandaram poucas explicações. Assim, poder-se-ia afirmar que o sistema está pronto e já está em teste quanto a sua aprendizagem e mediação da cultura escrita em língua de sinais em um curso de extensão, ofertado pela direção do Instituto de Educação da UFMT. Vele ressaltar que esta pesquisa é embrionária e não está pronta e acabada, outrossim, aberta a novas valorações.

Uma última parte do experimento foi analisado por Benassi, Duarte e Souza ${ }^{9}$ as leituras realizadas por um acadêmico visual (surdo) da Libras e por uma profissional/acadêmica da Libras. Na participação do estudante visual (surdo) que tem iniciação básica na ELiS, três sinais foram lidos com a demanda de algumas explicações prévias da ELS. Para esses autores:

A realização da leitura pelo acadêmico visual, traz a legitimação do sistema, pois tanto ouvintes quanto visuais realizaram leituras de sinais da Libras escritos pela VisoGrafia sem apresentar grandes

\footnotetext{
${ }^{8}$ PESQUISAR; CASA; SABER e ACREDITAR foram os sinais lidos por RS e LARANJA/SÁBADO; ENTENDER; ESTUDAR; BISCOITO foram os sinais lidos por LS.

${ }^{9}$ Texto em processo de finalização de escritura. Circulação restrita.
} 
dificuldades ou demandam por longos períodos de estudos (BENASSI, 2017, p. 111).

Sendo assim, fica comprovado a viabilidade da leitura da Libras escrita pela VisoGrafia, tanto por ouvintes quanto por visuais. Quanto a leitura realizada pela profissional e acadêmica da Libras nesta parte do experimento, os autores concluem que sua leitura foi realizada em um tempo relativamente menor a todos os demais, comprovando a eficácia do registro visual da Libras pela VisoGrafia. Dessa forma, os autores concluem que os procedimentos foram satisfatórios, tendo em tendo em vista que nenhum dos participantes dos experimentos, havia estudado a VisoGrafia na data da realização do mesmo.

\section{Considerações finais}

A grafia das LS ainda é encarada com descrédito por muitos na área dos estudos e pesquisas em Libras. Credita-se o registro escrito apenas a Segunda Língua (L2) e no que tange a Primeira Língua (L1), atribui-se apenas o status articulatório. No entanto, estudos e pesquisas já consagradas mostram que as LS não são ágrafas e que elas podem ser grafadas das mais variadas formas, tendo em vista, os muitos sistemas de ELS desenvolvidos ao redor do mundo nos últimos tempos.

Como apresentamos ao longo deste artigo, a VisoGrafia se configura como uma proposta de ELS viável, tanto em relação ao registro gráfico, quanto a sua descodificação, haja vista os experimentos satisfatórios registrados até o momento. Concluímos que o baixo número de caracteres essenciais ao registro gráfico visual da Libras pela VisoGrafia e sua fácil descodificação, a coloca no rol dos mais promissores sistemas de ELS.

Esperamos com isso propagar o conhecimento a respeito da ELS VisoGrafia, tornando um recurso didático eficaz na educação bilíngue, na forma escrita e leitura de L1 que auxilia a aquisição da escrita e leitura da L2. Este estudo é preliminar e não se constitui como acabado e fechado em si, logo, está aberto a novos olhares e valorações que possam contribuir para o seu crescimento.

\section{REFERÊNCIAS}

AGUIAR, T. C.; CHAIBUE, K. Histórico das Escritas de Línguas de Sinais. Revista Virtual de Cultura Surda. Edição n. 15, mar. 2015. Disponível em http://editora-araraazul.com.br/site/admin/ckfinder/userfiles/files/3\%20Artigo\%20para\%20REVISTA\%2015\%20 de $\% 20$ THIAGO $\% 20$ AGUIAR\%20e\%20KARIME\%20CHAIBUE.pdf. Consulta em 20 de outubro de 2015.

BARRETO, M.; BARRETO, R. Escrita de sinais sem mistérios. Belo Horizonte: Edição do autor, 2012.

BARROS, M. E. Libras por escrito. In.: Estudos. v. 33, n. 5/6, p. 385-396, mai./jun. 2006. http://revistas.ucg.br/index.php/estudos/article/viewFile/293/237. Consulta em 19 de nov. 2016.

BARROS, M. E. ELiS - Escrita das Línguas de Sinais: proposta teórica e verificação prática. Tese. Doutorado. Programa de Pós-graduação em Linguística. Universidade Federal de Santa Catarina. Florianópolis, 2008.

BARROS, M. E. ELiS: sistema brasileiro de escrita das línguas de sinais. Porto Alegre: Penso, 2015.

BENASSI, C. A.; DUARTE, A. S.; PADILHA, S. de J. Poiesis da Libras e da Escrita das línguas de sinais (ELiS): a utilização da visualidade da língua e da ELiS na poética de Duarte. In.: Revista Diálogos (RevDia). v. 3, n. 2, jul./dez. 2015. Disponível em http://periodicoscientificos.ufmt.br/ojs/index.php/revdia/article/view/3368/2365. Consulta em 19 de nov. 2016.

BENASSI, Claudio Alves; DUARTE, Anderson Simão; PADILHA, Simone de Jesus. Proposta 
de releitura do SignWriting e da ELiS. In.: Falange Miúda. v. 1, n. 1, 2016. Disponível em https://www.falangemiuda.com.br/index.php/refami/article/view/11.

BENASSI, C. A.; DUARTE, A. S.; SOUZA, S. A.; PADILHA, S. de J. VisoGrafia: uma proposta de grafia para as línguas de sinais. In.: VI Círculo - rodas de conversa bakhtiniana: literatura, cidade e cultura popular. São Carlos: Pedro \& João Eitores, 2016.

BENASSI, C. A. O despertar para o outro: entre as escritas de língua de sinais. Rio de Janeiro: Autografia, 2017.

COLÓMBIA. Ministerio de Educación Nacional. Instituto Nacional para Sordos (INSOR). Diccionario básico de la lengua de señas colombiana. INSOR. 2006.

DUARTE, A. S.; BENASSI, C. A.; PADILHA, S. de J. Sujeitos ouvinte e visual: da oralidade a visualidade. In.: Revista Diálogos (RevDia). v. 3, n. 2. jul./dez. 2016. Disponível em http://periodicoscientificos.ufmt.br/ojs/index.php/revdia/article/view/3371/2368. Consulta em 03 de jan. 2017.

ESCRITA de sinais. Site. Quem utiliza SignWriting. Disponível em https://escritadesinais.wordpress.com/2010/08/17/quem\%C2\%A0usa\%C2\%A0signwriting/. Consulta em 10 de abr. 2014.

FLEISCHMANN, M. E. S. de; PÉREZ, R. G. Manos con voz. Diccionario de lengua de señas mexicana. Col. Olivar de los Padres: Libre Acceso, 2011.

LESSA-DE-OLIVEIRA, A. S. C. Libras escrita: o desafio de representar uma língua tridimensional por um sistema de escrita linear. ReVEL, v. 10, n. 19, 2012. [www.revel.inf.br]. Disponível em http://www.revel.inf.br/files/6cf381ab909eeed796b069253a14d5ad.pdf. Consulta em 30 de mar. 2013.

NOBRE, R. S. Processo de grafia da língua de sinais: uma análise fono-morfológica da escrita em SignWriting. Dissertação. Mestrado em Linguística Aplicada. Programa Pós-graduação em Linguística aplicada. Universidade Federal de Santa Catarina. Florianópolis, 2011.

OVIEDO, A. Vuelta a um hito histórico de La linguística de lãs lenguas de señas: La mimographie de Bébian em el sistema de transcripción de Stokoe. Lenguaje, Universidad Del Valle, Cali. 2009, volume 37, no 2, p. 293 - 313. Disponível em $<$ http://revistalenguaje.univalle.edu.co/index.php? seccion=REVISTA\&revista $=37-2>$. Acesso em 25 set. 2013.

PEREIRA, V. M. Língua brasileira de sinais (Libras) no Mato Grosso: da regulamentação federal a implantação de ações em apoio a difusão da Libras. Monografia. Especialização em Educação Especial com Ênfase em Libras. Faculdade do Pantanal (FAPAN). Cáceres, 2016.

ROBERTSON, X. A.; QUINTELA, D. A.; RAMÍREZ, I. C. Diccionario bilingüe Lengua de Señas Chilena-Español Tomo II. Universidad Metropolitana de Ciencias de la Educación. Vicerrectoría Académica. Dirección de Investigación. Santiago: Impresos socías, 2009.

STUMPF, M. Escrita de Língua Brasileira de Sinais. Indaial: UNIASSELVI, 2011.

Recebido em: agosto de 2017.

Aprovado em: agosto de 2018.

Como citar este trabalho:

BENASSI, C. A. Visografia: uma nova proposta de escrita da língua de sinais. Traços de linguagem, v. 2, n. 2, p. 71-82, 2018. 